\title{
New Value: Keeping It Real
}

\author{
Peter Chamberlain \\ College of DAAP, University of Cincinnati, \\ Cincinnati $\mathrm{OH}$ 45221, United States of America \\ Email: peter.chamberlain@uc.edu
}

\begin{abstract}
Many parts of the world now swim in a sea of complex products that do not necessarily improve the overall quality of our lives. From cell phones to baby strollers, we have overloaded our designed environment with hyperfunctional products that often leave us searching for simpler, straighter forward product offerings. In a product landscape that more often than not equates complexity with sophistication; our ever-increasingly complex modern society has allowed faux conveniences to outweigh the tangible realness of our experiences. The look and feel of products has often become complex and complicated - and this is often highlighted as a positive thing. We are less likely to encounter simple, intuitive, and usable products geared toward the individual. To avoid this trap, one would need to apply a filter that would govern the intake of certain products to only those that are seen as adding true value to our lives. It is necessary to appeal to people's emotions, and carry cultural richness and authenticity back to the forefront while embracing the power of cur-rent and future technologies. Design has tremendous power and the versatility necessary to bring about this positive change.
\end{abstract}

Keywords: authenticity; cognition; culture; perception; simplicity; value.

\section{Introduction: In Over Our Heads}

We are in over our heads, it shows in many ways around the world. On a global scale we have simply over-extended ourselves. Our current global economic crisis has sent banks, major industries, and common everyday people reeling with uncertainty and instability. It has also been confirmed (again) that our activity on this planet has had negative and lasting impact. We are at another crossroads, and as a global community, as countries, as individuals we have begun the process of reassessing our priorities and values to positively impact the way that we live and our future outlook.

As members of the global community, we humans must find ways to sustain life, provide shelter for ourselves, and attempt to maintain a certain quality of our everyday lives. One of the ways in which we attempt to accomplish this is through the adoption of various consumer products. However, when we have accumulated the basic staple items that support or lives and which bring us pleasure in doing so, many of us keep searching for more. Microwave dinners

Received November $27^{\text {th }}, 2009$, Revised October $29^{\text {th }}, 2013$, Accepted for publication November $8^{\text {th }}, 2013$. Copyright () 2013 Published by LPPM ITB, ISSN: 1978-3078, DOI: 10.5614/itbj.vad.2013.4.1.2 
with even more variety and great taste, topical treatments that keep the cat from getting fleas for a longer period of time, cameras that allow one to capture even more beautiful images and save them for later, automobiles and motorcycles that move one around faster and faster, computers that help us do work more efficiently, much of the world is supersaturated with the myriad products that we feel we must have. As we tread water in this sea of products, it is becoming painfully obvious that these products purport to, but do not always actually improve the quality of our lives. From cell phones to baby strollers, we have overloaded our environment with hyper-functional products that promise the world, and suggest that only through their use can one rise to a higher level of being, better oneself (and with greater ease and convenience to boot). Because, it seems that most everyone is looking for an easier, faster, smoother way to do and get everything that they desire. As a result of this we can easily find ourselves living in a very visually noisy, physically cluttered environment that is packed with the next wonder product, one hundred times over.

Layer upon layer of complexity turns up in products in an attempt to exhibit a tremendous sense of value in an otherwise ordinary object, and far too often is complexity equated with sophistication. Often times we are left wondering, "why can't I just have a plain old cell phone, without a camera, without an mp3 player, without an electric shaver built in?"

In our ever-increasingly complex modern society, the conveniences are beginning to outweigh the tangible realness of our product experiences. The look of things has become complex and complicated, and this is often highlighted as a positive thing. We are less likely to encounter simple, intuitive, and useful products geared toward the individual, which celebrate the experience those products facilitate. As we look off into the sea of products, we can see waves of the same that seem as though they will endlessly arrive at our shores. We really must ask ourselves the question, are we any happier now than we were before we had all this stuff?

Where does this stuff even come from, and where does it go? When Americans shop the aisles of big box stores, most of us are not even remotely aware of the true cost of the hundreds, thousands of items on the shelf. We are very aware of the immediate cost to us, but when it comes to the impact on the environment, materials usage, transportation costs, and labor conditions and wages, we are for the most part at a loss.

By now we are all well aware that we are in deep trouble with Mother Nature. Engaging in non-renewable practices for far too long, and pumping irresponsible products into the world has added to the bleakness of the future of generations to come. Our future generations will likely have no alternative but 
to adapt to a new climate filled with floods and generally more extreme weather and all of the complications that this will bring. While the mass production of earth-unfriendly products is only one small part of the problem, it is definitely part of the problem.

It is clear that the way that we will soon be forced to consume will dictate the way that we should now design. All of this begs the question, at what point will the broader view of the true cost of a product make it onto the radar screen of the average consumer? What will it take to make a consumer choose a more responsible, healthier product that was easier on the environment to produce, was fair to all who had a hand in its creation, and which provides a high degree of intuitive usefulness in a meaningfully simple way and is very valuable to its owner?

The answer to this question is rooted in understanding how we define value and what dictates our value systems that carry us through our days.

\section{Discussion and Analysis: Value and Our Values}

Value is a very complex concept. It is what marketers attempt to interpret and communicate to would-be consumers; it is the sense that designers attempt to imbue in products. It is the factor that many consumers are not entirely aware of, and which directs much of their consumptive habits. The value that a person draws from a product is connected to the broader sense of the values by which that person lives their life. Value is lifestyle driven, addressing the qualities of a product that make it useful, usable, and desirable. People purchase products that enrich their experiences based on what is important to them, i.e., their values. The product must support that value base, and the more the product does support that base, the higher its perceived value [1]. If we were to associate product categories with the respective levels of Abraham Maslow's Hierarchy of Needs, we would see that products are much interconnected with our emotional wellbeing (see Figure 1). These things that we employ at our various activities allow us to sustain a healthy happy life, feel safe, connect with others, feel good about ourselves, and contribute to a greater good.

We are guided through our everyday lives by a variety of drivers. Whether one is guided by religion, culture, a personal set of experiences that have carved their perspective and which thereby influence their decision making, all of the above, or perhaps by no real system at all, freestyle. Regardless of what it is that grounds one's decision making, the majority of all people make decisions that will ultimately result in favorable as opposed to unfavorable results for themselves and their loved ones. We base our decisions on what we can imagine will result in a positive outcome. But the commonality more or less stops there, 
as value systems are a highly subjective and personal construct that become more and more specialized and specific as the lens zooms in on the individual person.
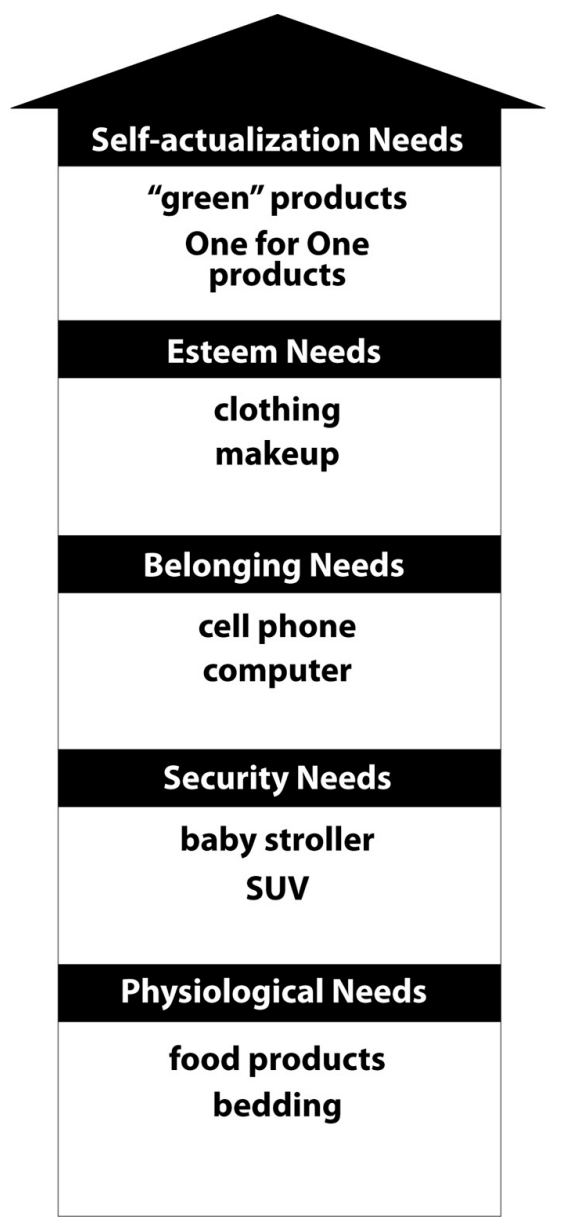

Figure 1 Product-Needs Association Diagram (adapted from Maslow's Hierarchy of Needs).

Everyone belongs to a tribe of other similar people with some level of common experiences and outlooks. At the macro level this could mean a person who belongs to the human race, at the micro level a person who is a member of a specific family living in a certain part of a neighborhood. One's culture plays a major role in determining how one employs perception and cognition to guide them through their daily life. The foundation of a person's particular cognitive or perceptual style is based largely in socio-cultural and environmental factors 
that influence the course of their psychological differentiation [2]. The rules of their society, the particulars of intrapersonal communication, the physical make up of their environment, as well as many other variables comprise the basis for the way that they see the world and make decisions.

These certain beliefs or rules, comprise a person's system of values. This is the hat that we put on when we wake up in the morning, when we interact with our family, when we enter public space, when we consider and select products to adopt at the store.

In the point of purchase environment, the behavior of consumers can turn on a dime, as the respective messages that products beam at consumers seek to find a "way in" to make a connection with them and establish approval. The complex interplay of emotion and reason in the mind of the consumer establishes notions such as perceived risk and intent to purchase [3]. These notions greatly affect a consumer's judgment in that first moment of truth and can ultimately decide if the product has found a new home or if it will stay on a store shelf.

\subsection{The Filter}

One example of the way that culture can affect how one's values come into play when adopting products is the Amish community. Spread across 27 American states live some 225,000 members of the Amish community. The Amish originated in Switzerland in the 1500s, and are characterized by their black horse-drawn carriages and traditional clothing. The Amish have a unique relationship with technology and the products that embody it. Many people think that the Amish reject any type of technology whatsoever. However, they are very particular in the variety and the extent to which they use technology. The Amish do not consider technology evil in itself but they believe that technology, if left untamed, will undermine worthy traditions and accelerate assimilation into the surrounding society, ultimately changing the foundation of their daily lives and social structure. Depending upon the particular family, or clan, different machines and products are permitted to be used. This filter that the Amish community uses to regulate its use of technology is a unique and effective societal construct.

Everyone has a filter of sorts that governs those things that they deem acceptable, valuable, useful, or perhaps inappropriate. Recently there seem to be some larger trends at work that are affecting people's filters regardless of nationality and culture. 
Some recent trends affecting perceived product value:

1. a turn back to traditional quality crafted products which are often intuitively visually understandable (products that revere the handcrafted methods of the past and which are non-taxing on our senses)

2. a yearning for simpler products that seamlessly support experience ("transparent" physical and graphical user interfaces that appeal to our precognitive processes and that just work)

3. an increased sense of holistic value in the products that we adopt (considerations about not just the price and convenience of products, but issues such as sustainability and responsible labor practices)

4. a craving for a genuine "realness" that products have largely been void of for years (the necessity to appeal to people's emotions, carry tradition and authenticity back to the forefront while embracing the power of current and future technologies)

\subsection{Keep It Simple}

It seems a natural urge to try and get every little thing possible into a product and its packaging. Often times there is so much packed into new products that any real message vying to be communicated is lost in the forest that is the complexity of the product. This can occur with the graphical user interface of an electronic product or in the packaging of a consumable food item. Many young Industrial Design students are convinced that the more functionality, the more versatility, the more obvious features that a product is perceived to have, will add value for its user. Nine times out of ten, the resulting products are those that achieve many things poorly, and none of them well, or worse yet are not usable at all.

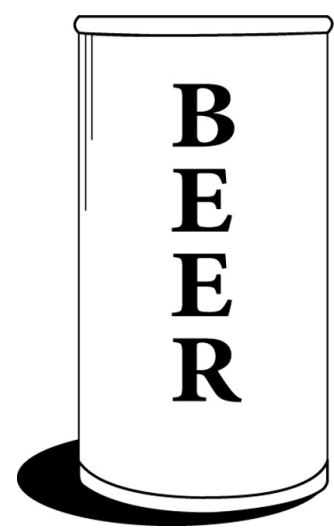

Figure 2 Can of Generic Beer. 
While it may appear that what is being suggested here is a simplification that strips away all brand identity and greatly limits the communicative ability of a product, this is not so. There are a number of examples in products across various categories that have quite simply and elegantly communicated volumes about the product and have provided seamless and highly usable user/product interaction. When all of the superfluous features, unnecessary functional, and graphical elements are taken away, one isn't necessarily left with a characterless, generic product such as a generic can of beer (Figure 2). Just as silence is a meaningful and beautiful component of music, simplicity has a place in products.

In the marketplace we are faced with way too many choices, and we are overloaded with visual information that reduces the likelihood that we will be able to find what we are searching for. In our homes we are tormented by the regenerating volumes of objects that are piling up, all of the objects that at one point we were convinced that we couldn't live without, but which now seem to have become burdensome.

\subsection{Embrace the Source}

At a point in history when the world shows interest in becoming more united, and when we are faced with truly global issues that we must address as one large community, we must embrace the cultural character of new products. What if Chinese products were appreciated worldwide primarily because of the certain sensibility that they brought, a uniqueness of form and sensitivity that was based in that particular culture, rather than just playing the role of the least expensive alternative in a western big box store? In the case of China, this certainly seems like what is coming down the pike. There is, however, the worry that in all of the haste in ramping up to redefine design and become a global center for hot products, that the richness of this culture may be lost to some degree. It's easy for westerners to have this view, as we hear and read stories about China's interest in automobiles rivaling that of bicycles - the magnitude of bicycle use is one of the many things about Chinese contemporary culture that always interests us. There is no real doubt that China will become a design force with which to be reckoned, but what about other countries? Will other countries ever get a chance to show the rest of the world what they've got?

What do the sensibilities and character attributes of a country look like as manifest in a product? Understanding the meaningful and underlying value that one's culture has to offer the world of product design, and offering contributions based in that value needs to happen more often. It's time to celebrate differences. 
Rather than a brazen stereotype, the below image (Figure 3) of a t-shirt imprinted with a common statement about the specific qualities of different peoples of the world, suggests that there are certain qualities associated with nationality that could preclude one to marked success. What would the product version of this t-shirt read if an inclusive environment that highlighted cultural richness in design were fostered? - it could become quite verbose.

International design and manufacturing networks that employ local artisans to mass produce products rooted in traditional craft, which are simple, are considerate of the holistic value of the products, and which appeal to people all over the world are one way to further such an initiative

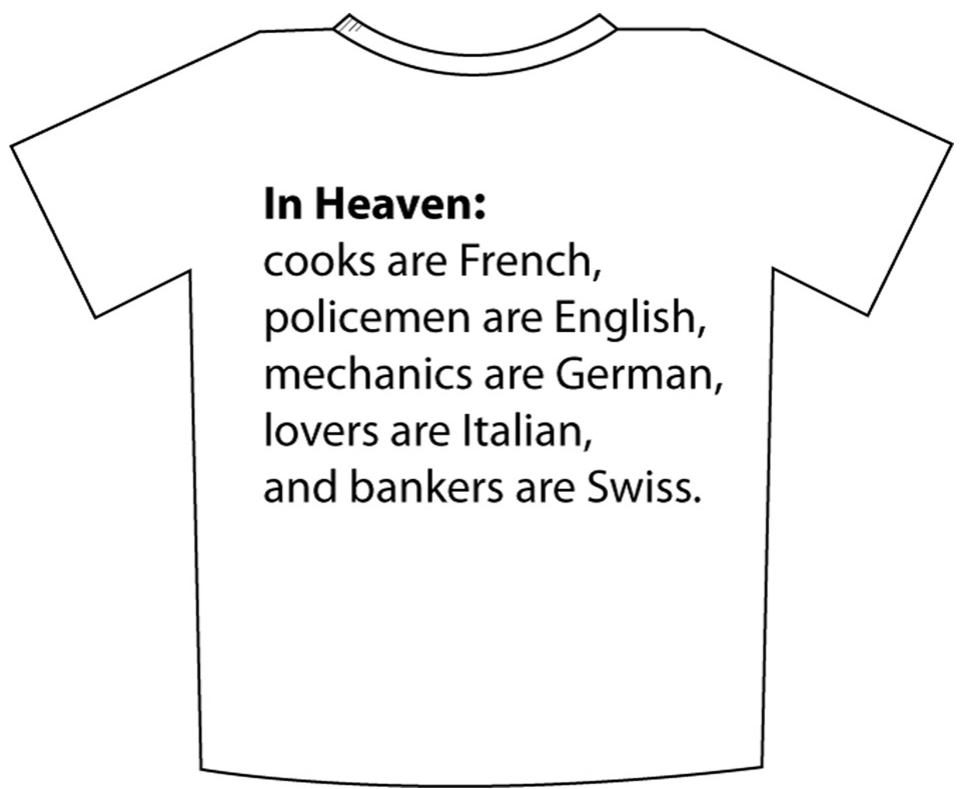

Figure 3 "In Heaven" T-shirt.

\section{Results: The Role of Design}

Designers by nature are interdisciplinary problem solvers who vehemently pursue solutions to many of the harder to solve problems in our lives. Since understanding disciplines such as Engineering, Social Sciences such as Anthropology, and Business is second nature to designers, they are able to build meaningful bridges between these otherwise disparate fields. Corporations have only just begun to fully embrace the power of design, but they have begun to do so with considerable enthusiasm. 
Proctor and Gamble CEO A.G. Lafley, who learned about the power of Design to positively affect people's lives through the design of outstanding products and everyday experiences while in Japan, has embraced design as a powerful and important resource. He states, "Good Design is the catalyst for creating total experiences that transcend functional benefits alone and delight consumers". The particular type of abductive thinking that design schools employ ensures that the new, young designers graduate with a forward-looking vision of what might be possible [4]. As design is seen as one way to ultimately create happiness with consumers by providing them the quality experiences that they desire, the global business community is embracing it as a means to enable them to become more robust. Educational institutions can play a leading role in bringing about positive future change. As new waves of graduates leave the halls of a Design School, they will be the ones who influence the corporate design departments and consultancies, or begin their own burgeoning practices. They will be the ones who breath the next new breath into the endeavor of developing new products that provide appropriate and optimal value to users, through sustainable means, while celebrating cultural richness and simplicity.

\section{Conclusions}

At a time when so much is being reassessed because of the global economic crisis, design and industry should be poised for the call to duty. It is quite clear that we are on the cusp of real change. Trends of simplification, traditional quality craft, a sense of holistic value, and presence of genuine realness are all being increasingly sought in the makeup of products. Additionally, embracing the cultural character of products will add value and authenticity to the experience of interacting with those products. All of this change has broad implications, as imbuing products with these new values could change the face of the global consumption model. By harnessing the skill of the craftsman and applying future technology appropriately in meaningful and useful ways, the economies of developed nations could be pulled back up from economic crises, and developing countries could be given a leg up on their road to increased strength and independence. More people would have the wonderful opportunity to adopt meaningful products that are intuitive, useful, and are of worthy cherishing.

\section{References}

[1] Cagan, J. \& Vogel, C. 2002. Creating Breakthrough Products, Upper Saddle River, NJ. Prentice Hall PTR.

[2] Witkin, H.A. 1965. Psychological Differentiation and Forms of Pathology, Journal of Abnormal Psychology, 70, pp. 317-36. 
[3] Chaudhuri, A. 2006. Emotion and Reason in Consumer Behavior, New York, Elsevier.

[4] Lafley, A.G. \& Charan, R. 2008. The Game-Changer, New York, Crown Business. 